\title{
Guide for Automation of Low Volume Production
}

\author{
Malin LÖFVING ${ }^{\mathrm{a}, \mathrm{b}, 1}$, Peter ALMSTRÖM ${ }^{\mathrm{b}}$, Caroline JAREBRANT ${ }^{\mathrm{c}}$, Boel \\ WADMAN $^{\mathrm{c}}$, Magnus WIDFELDT ${ }^{\mathrm{c}}$
}

${ }^{a}$ Träcentrum Nässjö Kompetensutveckling AB, Nässjö, Sweden

${ }^{b}$ Chalmers University of Technology, Gothenburg, Sweden

${ }^{c}$ RISE, Mölndal, Sweden

\begin{abstract}
There is a remaining need from both academia and practitioners, to gain further knowledge about the decision making process for automation of low volume production. This paper includes insights of drivers for automation, the development of a guide for low volume production and the outcome of using the guide. The research in this study is based on both empirical data and theoretical considerations. The empirical data was collected in five case studies and a questionnaire. This paper is part of a research project with the main objective to develop knowledge about how flexible automation may contribute to improvements in efficiency, ergonomics, quality and production economics in different industries with low volume production. One of the results in the project was a comprehensive guide, developed, refined and improved in an iterative collaborative process, where tools and parts of the guide were tested and verified by five manufacturing case companies. The paper describes briefly the development process of the guide and content. The requirements of the guide derived from literature, case companies, questionnaire as well as industrial experts. The resulting guide can be used in several ways, depending on the requirements of the application. The guide includes guiding principles, a decision model for the analysis of the company, choice of automation and facts about automation. In the end of the project, four companies had invested or decided to invest in different types of automation.
\end{abstract}

Keywords: Flexible automation, decision model, automation investment

\section{Introduction}

Customers' demand for variety in products leads to needs for production with lower volumes and higher mix of products. At the same time does automation play a vital role in modern manufacturing, as the main incentives to automate manufacturing is to improve productivity, improve quality and reduce cost as well as get rid of monotous working tasks [1]. However, for manufacturing companies with low volume production it may be a risk to invest in complex automation technology suitable in the production today, as they continuously introduce and produce new products. Even though the incentives of automation are well-known by practitioners and researchers [1,2,3], many of the manufacturing companies with low volume production, do not believe it is possible to automate low volume production or that an automation investment can pay off. As the

\footnotetext{
${ }^{1}$ Corresponding Author. malin@tracentrum.se
} 
development of automation technology is fast, there now exist automation technologies suitable for low volume prodution [4] and this opens up for new automation investments in companies that traditionally have not invested in automation.

The decision to invest in automation may imply possibilities or even be crucial to strengthen a company's competitiveness $[3,5,6]$. Previous research studies show that the automation technology investments are not always successful [2,6,7]. Automation technology investments can fail due to lack of realistic or defined objectives and structured plans $[6,8]$. There exists a vast array of literature on decision models for advanced manufacturing technologies including automation technologies [see for example 9,10,11], but the majority of the decision models are conceptual and not tested emprically. The existing empirically tested models either focus on qualiative analysis [see for example 12,13] or quantitative analysis of ecomony [11]. Only few of them take an overall production system perspective [13]. Moreover, there is a lack of methods and guidance for automation investment for low volume production. Therefore, there is a remainig need to develop a guide for automation of low volume focusing on quantitative analysis of the total economy, supplemented with more qualitative analysis of consequences for the entire production system. The purpose of the paper is to present a guide for automation of low volume production. The paper includes reflections of the development of the guide and the outcome of using the guide.

\section{Theoretical considerations}

\subsection{Decision models for Automation Investments}

There exist numerous decision models for advanced manufacturing technologies including automation technology [see for example 14]. Many of these decision models focus on technology selection and justification and they are commonly classified as strategic, economic, analytical or hybrid models [8]. The strategic models are often based on qualitative analysis while the economic and analytical models are based on quantiative analysis. Most of the models are conceptual. There hybird models often focus on strategic and ecnomic analysis $[8,10,15]$. There is also limited empirical evidence to support whether they are actually used by practitioners [11] and their usability has not been analysed. One empirically tested model for automation decision is the "Lean Automation Handbook" [13]. The handbook is extensively tested in companies and include several qualiatitve analysis. Another method, exentsively tested at companies, is the evaluation of automation level model including qualitative analysis of suitable level of automation [12].

\subsection{Production Economics and Productivity}

One of the main incentives for automation is cost reduction [1]. When investing in automation, focus has often been on reduction of personnel. However, to understand the cost of automation in a production system perspective, a broader view is needed. Windmark and Andersson [16] developed a cost model with a broader perspective, including more aspects than just personnel costs. There exist also other methods including both productivity and cost for production system such as the capacity frontiers framework [17] and Productivty Potential Assessment [18]. 


\subsection{Production Ergonomics}

Another incentive for automation is to improve ergonomics and elimnate or reduce monotounsous jobs. The introduction of new technology and automation affects employees' working conditions, both physically and mentally. The working tasks are changed, new demands arise and new skills are demanded. Here appear both opportunities and risks regarding ergonomics. For ergonomic improvements and to survive and become lasting, integration into production systems and regular development is required, where the results are managed and integrated by already existing working groups [19]. If ergonomics is not integrated, the improvements will not be sustainable over time, and will be reversed in other changes in the production system [20].

\section{Research Methodology}

This paper reports from a project on flexible automation for low volume production. The main objective was to develop knowledge about how flexible automation may contribute to improvements in efficiency, work organization, ergonomics, quality and production economics in different industries. Based on the findings, a comprehensive guide was developed, briefly presented in this paper.

The research in this study is based on both empirical data and theoretical considerations. The empirical results is based on five case studies and a questionnaire. The case studies were carried out in five manufacturing companies: A, B, C, D and E in 1,5 years period. The case companies represented different industries with varying ownership and size. However, they all considered themselves as having low volume production and wanted to gain more knowledge about automation appropriate for their production. Several of the companies also had high mix of products. Low volume production is often associated with smaller manufacturing companies, but in this study also a larger company in process industry participated. According to [1] low volume is usally described as 1 to 100 units each year. However, low volume production was defined differently by the participating companies, and depend on the products manufactured in the company. In one case company, one product was the usual size of a batch, while in the larger process company, several thousand was the norm for low volume production.

The data collection at the companies included interviews, observations, work sampling studies and tests of parts of the guide, see Table 1. Initally, one strategic interview and one observation were made at each companies, in total five initial interviews and five initial observations. An interview gudie was developed and used for in depth interviews with decision makers. The interviews lasted between 60 minutes to 120 minutes. In three cases the interview was a group interview, including two to three decision makers such as owner/CEO, production manager, sales manager, technical manager. The themes for interviews were: description of the company, customers today and tomorrow - what products they buy, production process and material flows, production steps, work tasks and automation level, organization of work, competence, safety, occupational health and sick-leave. The questions were asked in order to clarify and define the companies' development needs, demands for automation and their next step in the automation decision. Observations in manufacturing were conducted to get a deeper understanding of both the production system and specific parts in the production. Work sampling studies were used to identify total work time used for specific activities 
in the production. The specific activitites were manual activitites with potential to be automated. Work sampling studies were made once or twice at all the case companies and they lasted 2 to 6 hours. During the study, informal follow-up meetings and interviews were made continusly with the decision makers. The data collected were documented and analysed and the findings were used to develop and refine the guide.

Table 1. Data collection techniques in the case companies

\begin{tabular}{|l|l|l|l|l|l|}
\hline Activity $\backslash$ Company & \multicolumn{1}{|c|}{ A } & \multicolumn{1}{|c|}{ B } & \multicolumn{1}{c|}{ C } & \multicolumn{1}{c|}{ E } \\
\hline Strategic interviews & Yes & Yes & Yes & Yes & Yes \\
\hline Observations & Yes & Yes & Yes & Yes & Yes \\
\hline $\begin{array}{l}\text { Work sampling studies } \\
\text { productivity) }\end{array}$ & $\begin{array}{l}\text { Yes } \\
\text { 6h at one } \\
\text { automation } \\
\text { candidate }\end{array}$ & $\begin{array}{l}\text { Yes } \\
\text { processes at a } \\
\text { work stations } \\
\text { with flexible } \\
\text { automation }\end{array}$ & $\begin{array}{l}\text { Yes } \\
\text { automation } \\
\text { candidates }\end{array}$ & $\begin{array}{l}\text { Yes } \\
\text { At two work } \\
\text { stations. } 4 \mathrm{~h} \text { at } \\
\text { the other } 1 \mathrm{~h} \text { at }\end{array}$ & $\begin{array}{l}\text { Yes } \\
\text { tial automa- } \\
\text { tion candidates }\end{array}$ \\
\hline $\begin{array}{l}\text { Ergonomic and } \\
\text { psychosocial analysis }\end{array}$ & Yes & Yes & Yes & Yes \\
\hline $\begin{array}{l}\text { Production mapping } \\
\text { Production economic } \\
\text { model }\end{array}$ & Yes & Yes & Yes & & \\
\hline
\end{tabular}

To get a broader understanding of reason for automation and driving forces a total of 34 participants from 18 companies other than the case companies responded to a questionnaire on reasons for automation.All participants answered the questionnaire. The questionnaire included eight defined drivers of automation. The drivers were chosen from a mix of experiences, dialogues within the project and literature. The survey was done in parallel with the case studies and the development of the automation guide, at a number of seminars on automation principals and trends. The participating companies in the survey had different numbers of employees, ownership and belonged to different industries etc. They had varied experiences in automation, but all had a genuine interest in production development including automation,

Each informant selected, based on the defined options, the most important driver of automation, the second most important driver and the third most important driver. The results were analysed and concluded. The results of the questionnaire were used to strengthen and verify the design and the contents of the automation guide.

The theoretical considerations in this paper are based on literature reviews and previous expericences of the researchers and authors of this paper. The researchers in this paper have different theoretical backgrounds, and they made their own literature review for their specific area such as production economy and productivity, production ergonomics and materials flow. The theoretical considerations were the base for the development of the guide together with the case companies requirements that were identified in the initial interviews.

The empirical data included the case companies and questionnaire were analysed in an iterative process during the project. For this study, each case was first analysed indiviudally and thereafter there were a cross-case analysis. The findings from each case 
and cross-case analysis analysed against the questionnaire and exising literature. The findings constitutes the base for the discssion and conclusion.

\section{Drivers for automation}

In the interviews at the case companies, ergonomics was mentioned as a main driver by the case companies as automation can do monotonous or heavy working tasks instead of an employee. Other drivers mentioned by the case companies were cost reduction and improved productivity. The companies also described understanding of possibilites for automation and learning about automation as drivers for automation investments.

The results of the questionnarie indicates that the most important main driver of automation was increased productitvy, 20 representatives regarded this as the main driver for automation, see Table 2. Improved ergonomics was ranked as the second most important driver. Cost reduction and improved quality were also prioritized by the companies, but not as the main driver. After these four drivers there was a gap in the ranking, see Table 2 .

Table 2. Main drivers of automation. Number of informants: 34 . Importance $=$ sum weighted results, most important ' 3 , second most ' 2 , third most ' 1

\begin{tabular}{|l|c|c|c|c|c|}
\hline Drivers of automation & No 1 & No 2 & No 3 & Sum of all votes & Importance \\
\hline Increased productivity & 20 & 7 & 1 & 28 & 75 \\
\hline Improved ergonomics & 4 & 10 & 12 & 26 & 44 \\
\hline Cost reduction & 4 & 8 & 2 & 14 & 30 \\
\hline Improved and stable quality & 3 & 4 & 12 & 19 & 29 \\
\hline Improved throughput time & 1 & 2 & 2 & 5 & 9 \\
\hline Hard to find operators & - & 1 & 4 & 5 & 6 \\
\hline Tracking possibilities & - & 1 & 1 & 2 & 3 \\
\hline Flexibility & 2 & 1 & - & 3 & 8 \\
\hline Others & - & - & - & 0 & 0 \\
\hline
\end{tabular}

\section{The Automation Guide: Requirements, development and learnings}

\subsection{Requirements}

The requirements of a guide for automation were derived from the theoretical considerations, previous experiences by the research team, representatives from an union and industry associations, an automation solution supplier and the case companies. The guide should:

- Integrate productivity, ergonomics and economics

- Provide companies with self-help, be a guide for automation decision

- Be easy to use for production technicians or production managers in small and medium-sized enterprises (SMEs) with low volume production

- Be based on and stimulate participation

- Include transparancy and visualization

- Aim for long term gain and sustainability

- Be built on existing knowledge that can be adapted and adjusted to suit automation decision for low volume production 


\subsection{Development of a guide for automation}

To develop an industrial useable guide, we identified existing decision models and tools for productivity, ergonomics and production economics, as well as overall checklists to understand what models that were most suitable for automation decision for low volume production. For the productivity part, the Potential Productivity Assessment [18], capacity frontiers method was the foundation. Results from Windmark och Andersson [16] were used as foundation for the production economic model. The ergonomic part involved physical exposure and psychological strain. The assessment of physical exposure is a screening, based on recurring factors in several existing methods combined with quantitative values by estimating the proportion of each factor in the tasks. For assessment of psychological strain, parts of the Potential Productivity Assessment [18] were used.

The draft guide was successively developed, adapted and adjusted in an iterative and collaborative process. In this process, the five companies continuously tested different tools and parts of the guide. Representatives from the case companies, research team and an automation solution supplier evaluated the results of the tests, and iteratively refined and improved the tools and different parts of the guide into a final version. The guide was gradually expanded to also include new parts and guiding principles and the three initial parts were intergrated into a decision model. Here, the results of the questionnaire were used to further understand what to be included (or not included) in the guide. The tests and activities undertaken at the five case companies are summarized in Table 1.

\section{The Automation Guide: A flexible and pedagogical tool}

The automation guide is divided into three sections:

1. Guiding principles for automation

2. Decision model for the analysis of the company and choice of automation

3. Facts about automation and robotics

The guiding principles for automation include:

- Automation as a mean to create both competitiveness as well as more stustainable work stations

- Identify and remove waste before automation

- Put safety first

- Start simple, then increase level of complexity and difficulty

- Maintain the layout as changes can be expensive

- Understanding requirements for handling in the manufacturing process

- Adaptation of the products for automated production

The decision model offers guidance through the automation decision process, beginning with the company on an overall strategy level and alignment of strategy to the automation decision. Thereafter, the decision model is divided into a four step model, see Figure 1, that leads to the automation decision investment. Step 1 includes questions about automation and the company's prerequsities for automation. Step 2 includes a 
production mapping to understand the overall system and which work station that is suitable for automation. This work station is analysed further. Analysis in Step 3 includes analysis of the whole workstation, operators activitites and ergonomics including work content. Step 4 includes the production economy model, focusing on productivity and effects of the investment. These analyzes and mappings lead to the last step; the decision. Each part also include recommended tools such as deeper production mapping, work sampling studies and ergonomics.



Figure 1. The decision model for automation investment

The complete automation guide is available in Swedish as well as in English. The Swedish version is also available in a web format and can be accessed at www.edig.nu/swedprod.

\section{Outcome of using the guide}

The empirical outcome of the project was that four of the five case companies had invested or decided to invest in automation.

Company A had invested in flexible and moveable automation solution before the beginning of the project, but the automation solution was implemented during the project. The company did not make any other automation investment decisions during the project.

Company B had invested in flexible and moveable automation soluation before the beginning of the project, but the automation solution was implemented during the project. At the same work station as the flexible automation solution, the company invested in an used robot during during the project. During the project, they also decided to invest in a robotic cell for another work station. This robotic cell was implemented in 2019, after the project ended.

Company $\mathrm{C}$ had several ideas of potential work stations suitable to automate, and one work station was studied further. However, after a production mapping and strategic analysis, the company decided to not automate the work station, but another work station. They also decided to improve the material flows.

Company D wanted to learn about automation and where to use it in manufactuirng. The research team studied two different work stations, and one of the work stations was 
identified as suitable to automate. They decided to invest in a collaborative robot in this cell during the project.

Company $\mathrm{E}$ decided to invest in a robotic cell during the project in order for operators to learn about automation as well as to increase productivity in the work station. The work station was identified by both the research team and company as potential automation candidate. The cell included a machine, a used traditional industrial robot and new material handling equipment. The company aquired a used robot from a company in their company group. Due to delays from the machine supplier considering integration, the robotic cell was not implemented during the project.

\section{Discussion}

The literature on automation for low volume production and flexiblity is very limited, just like literature on automation in SMEs. Low volume production with high variation and flexibilityis often related to a low level of automation [see for example 21,22]. The research project focused on the today existing flexible automation for low volume production, the needs in companies and their decision process for automation. Flexible automation is automation technology that can perform a variety of industrial tasks and is not decidated to one machine or one product and therefore assumed to be more suitable for companies with low volume production The companies that participated in the project had interest of automation with such flexibility. The findings from this study is that the case companies invested in different types of flexible automation depending on prerequsities and needs based on their low volume production.

A lesson learned from the guide development process, was the significance of the companies readiness for automation. Readiness means to have the right competence and knowledge of automation specifications, investments and implementation on several organisational levels. In the smaller case companies this means that both operator, production manager and chief executive/owner were involved in the automation decision. It is vital that the operators are involved and engaged as early as possible, as they should learn to handle the automation.

The manufacturing steps, including material flows, work stations and all manufacturing operation steps, need to be identified, mapped and analysed in order to understand where and how automation can be used as a value-added activity.

A work station in one company was identified as a candidate for automation. After a work sampling study of this work station was performed, the results showed that the work station was not a candidate, for several reasons such as lack of spare parts and unclear flow. To understand the manufacturing and identify value-added activites, a production mapping was conducted. Literature [22] describe that companies need to eliminate waste before introducing automation. If not, waste, i.e. non-value-added activities, may be automated. Lessons learned from this was to add some principles in the guide, inspired by lean [24], but adapted to support decisions on flexible automation. Such an approach is found in [13], but without focus on flexible automation for low volume.

Automation implies changes in the system and work environment, for example new work tasks for the operator and changed utilzation of the equipment. Before investing in automation, these changes need to be considered as they may affect both the overall production system and work tasks for the employees. Therefore, a scenario analysis is 
essential, to understand what can be done with the capacity of both employees and equipment and the released working time. Due to this, analyses of several capacity effects are included in the production economic model in the guide.

The different case companies had slightly different requirements of the guide and reasons to automate. Several of the case companies wanted to get rid of monotonous and heavy working tasks. Other reasons for automation was to reduce cost or to get knowledge about automation. This lead to a flexible guide, flexible in terms of that the different parts in the guide could be used separately. Due to this, the guide also includes a user manual and recommendations of exisiting tools, such as work sampling studies, ergonomic analysis as well as a different way of calculating cost for the investment. Moreover, the needs and reasons for automation in the case companies also affected which part of the guide they tested. This flexibility has not been included in previous automation decision models.

Based on the results of the initial interviews with the case companies, a strategic part was included in the guide. The strategic part evolved during the project, first focusing on manufacturing strategy, and later developed into an overall map on how to align strategy with automation decisions. The strategic part was also used by the research team as a data collection technology to visualise and discuss the development of the each case company. Several of the existing automation decision models include strategic parts $[5,6,8,13]$. Often, these models focus on quantiative analysis, while the strategic part in this guide focus on how to align strategy with automation. Research has shown that automation decisions, aligned with strategy, tend to be more succesful than automation decisions not aligned [7].

The ergonomic screening template in the guide was appreciated by the companies, especially the relative simplicity of estimating the physical exposure to get an initial screening. The experience is that the screening is illustrative and possible for the companies to do on their own.

The main drivers for automation identified in the questionnaire (Table 2) were increased productivty, ergonomics and cost reduction, and this is verified in literature by for example [1]. A recent global survey about automation conducted with 85 OEMs and described in [2] ranked reduction of cost, improved quality, improved productivity and improved capabilities of robots as the main driver for investment in automation. The difference between the results of this questionnaire in this paper, and the survey in [2] may depend on the number of employees and experience of automation in the companies participating. In [2], the OEMs that participated in the survey were large global companies, while in the questionnaire in this paper, the majority of companies were SMEs in one country. SMEs have not invested in automation to the same extent as larger companies and they have different characteristics and requirements on automation than larger companies. This can be one explanation of why productivity was ranked most important in the questionnarie and not in the global survey described in [2]. The difference is also emphasised in the case study. The case companies had different reasons to automate, and many of them described flexibility and ergonomics as the main drivers for automation. This difference may depend on the selection of case companies in the research project. The case companies wanted to participate in the research project due to their interest in flexible automation for low volume production. 


\section{Conclusion}

Automation for low volume production is gaining more and more interest from both practitioners and academia. To facilitate the automation decision process for companies with low volme production, a guide for automation of low volume was developed. The foundation of the guide was earlier research in different areas such as production economics, productivity and ergonomics and the final version of the guide also includes theories about strategy and materials flow. Previous research has inspired the development and results and experiences in these areas have been adjusted and adapted to suit automation for low volumes. The guide is flexible and separate parts can be used independently. The different parts in the guide also include recommendations of useful tools for deeper studies and understanding.

In general, the main drivers for automation are increased productivity and ergonomics, Table 2 . The reserach project concerns questions about flexibility for low volume and often high mix of products. The design of the guide is based on a generic decision process, how to evaluate and decide for automation, Figure 1.

The main results from the reserach project are:

- Five companies increased their knowledge on automation for low volume production as a way of improving competitiveness and ergonomics.

- The automation guide was created as a flexible tool for different requirements..

- Four of the case companies invested in or decided to invest in different types of flexible automation depeding on their prerequisites and needs based on the their product mix and manufacturing volumes.

The guide will in future be further developed, including more tools useful for specific low volume high mix manufacturing, in a continuation project. Two of the case companies will participate as well as three new companies from different sectors and with different number of employees.

\section{Acknowlegdement}

The authors wish to thank Vinnova, the Swedish Governmental Agency for Innovation Systems for their financial support. The authors also want to thank the project partners in the project.

\section{References}

[1] M.P. Groover, Automation, production systems, and computer-intergrated manufacturing, Prentice Hall pper Saddle River, 2007.

[2] McKinsey \& Company, Industrial Robotics Insights in the sector's future growths dynamics, July 2019.

[3] International Federation of Robotics, 2017, The impact of Robots on productivity, employment and jobs, Accessesed 22.11.2019. [Online]. Available:

https://ifr.org/downloads/papers/IFR_The_Impact_of_Robots_on_Employment_Positioning_Paper_upd ated_version_2018.pdf

[4] M. Löfving, P. Almström, C. Jarebrant, B. Wadman, and M. Widfeldt, Evaluation of flexible automation for small batch production, Procedia Manufacturing, vol. 25, 2018, pp. 177-184. 
[5] T. Baines, An integrated process for forming manufacturing technology acquisition decisions, International Journal of Operations \& Production Management, vol. 24, issue: 5, 2004, pp.447-467.

[6] M.K. Thomassen, B. Sjøbakk, and E. Alfnes, A strategic approach for automation technology initiatives selection, In B. Grabot et al. (eds.): APMS 2014, Part III, IFIP AICT 440, pp. 288-295, 2014.

[7] K. Säfsten, M. Winroth and J. Stahre, The content and process of automation strategies, International Journal of Production Economics, vol 110, issue 1-2, 2007, pp. 25-38.

[8] M.H. Small, Planning, justifying and installing advanced manufacturing technology: a managerial framework, Journal of Manufacturing Technology Management, vol. 18, 2007, pp. 513-537.

[9] B. Naik and A.K. Chakravarty, Strategic acquisition of new manufacturing technology: a review and research framework, The International Journal Of Production Research, vol. 30, issue 7, 1992, pp. 15751601.

[10] M.H. Small.and I.J. Chen, Investment justification of advanced manufacturing technology: an empirical analysis, Journal of Engineering and Technology Management, vol.12, issue 1-2, 1995, pp.27-55.

[11] N. Iakymenko, E. Alfnes and M.K. Thomassen, A differentiated approach for justification of advanced manufacturing technologies. Advances in Manufacturing, vol. 4, issue 3, 2016, pp. 257-267.

[12] Å. Fasth, Quantifying Levels of Automation-to enable competitive assembly systems, Chalmers University of Technology, Gothenburg, 2012.

[13] A. Granlund, M. Wiktorsson, N. Friedler and S. Grahn, Lean automationsutveckling Handbok, Mälardalens Högskola, 2016.

[14] F. Raafat, A comprehensive bibliography on justification of advanced manufacturing systems, International Journal of Production Ecnomics, vol. 79, 2002, pp. 197-208.

[15] A. Langley and J. Truax, A process study of new technology adoption in smaller manufacturing firms, Journal of Management Studies, vol. 31, issue 5, 1994, pp. 619-652.

[16] C. Windmark and C. Andersson, Cost modelling as decision support when locating manufacturing facilities, International Journal of Production Management and Engineering, vol. 4, issue 1, 2016, pp. $15-27$.

[17] R. Hedman, Capturing the Operational Improvement Potential of Production Systems, Chalmers University of Technology, Gothenburg, 2016.

[18] P. Almström and A. Kinnander, The productivity potential assessment method: Assessing and benchmarking the improvement potential in manufacturing systems at shop-floor level, International Journal of Productivity and Performance Management, vol. 60, issue 7, 2011, pp. 758-770.

[19] W.P. Neumann, M. Ekman J. Winkel, Integrating ergonomics into production system development - The Volvo Powertrain case, Applied Ergonomics, vol. 40, 2009, pp. 527 - 537.

[20] R.H. Westgaard and J. Winkel, Occupational musculoskeletal and mental health: Significance of rationalizaion and opportunities to create sustainable production systems: A systematic review, Applied Ergonomics, vol. 42 ,2011, pp. $261-296$.

[21] M. Wiktorsson, A. Granlund, M. Lundin, and B. Södergren, Automation and flexibility: An apparent or real dilemma?, In Innovative Quality and Improvements in Operations. Springer, Cham, 2017, pp. 35-48.

[22] T. Hill, Manufacturing Strategy: Text and Cases. Irwin/McGraw-Hill, 2000.

[23] T. Bortolotti and P. Romano, Lean first, then automate': a framework for process improvement in pure service companies. A case study, Production Planning \& Control, vol. 23, issue 7, 2012, pp. 513-522.

[24] J.K Liker, The toyota way. Esensi, 2005. 